\title{
Abstract: Premature Adoption of Technological and/or Administrative Innovations in Marketing: Exploring the Issues and Implications Through a Competitive Advantage Lens
}

\section{Radha Appan and Sreedhar Madhavaram}

\begin{abstract}
As seekers of reactive and/or proactive innovations in search of competitive advantage, firms often, prematurely, adopt technological and/or administrative innovations. The adoption of such innovations can be premature in two ways: the innovation itself is in its infancy or the firm is not ready for adoption. While the adoption of technological as well as administrative innovations is important, in this research, the focus is on the adoption of administrative innovations. We systematically explore and synthesize research on adoption of administrative innovations to develop a framework to explicate premature adoption of administrative innovations. Next, we review specific administrative innovations such as market orientation strategy, and customer lifetime value framework to explore premature adoption of administrative innovations in marketing. Finally, we discuss the implications of this research for theory and practice. Given the paucity of research on this issue in the marketing discipline, we hope that our work sparks productive inquiry into premature adoption of administrative innovations in marketing.
\end{abstract}

R. Appan $(\bowtie) \cdot S$. Madhavaram

e-mail: r.appan@csuohio.edu; s.madhavaram@csuohio.edu 